\title{
Anatomic repair for congenitally corrected transposition of the great arteries
}

\author{
Rajesh Sharma, ${ }^{\text {a,b,c }}$ Sachin Talwar, ${ }^{\mathrm{b}}$ Ashutosh Marwah, ${ }^{\mathrm{a}, \mathrm{c}}$ Sejal Shah, ${ }^{\mathrm{a}}$ Sunita Maheshwari, ${ }^{\mathrm{a}}$ Pujari Suresh, ${ }^{\mathrm{a}}$ Rajnish Garg, ${ }^{\mathrm{a}, \mathrm{b}}$ \\ Bijender Singh Bali, ${ }^{\mathrm{acc}}$ Rajnish Juneja, ${ }^{\mathrm{b}}$ Anita Saxena, ${ }^{\mathrm{b}}$ and Shyam Sunder Kothari ${ }^{\mathrm{b}}$
}

Objective: Anatomic repair is being actively evaluated as the preferred option for congenitally corrected transposition of the great arteries. We present our 13-year experience with this approach.

\begin{abstract}
Methods: Between May 1994 and September 2007, 68 patients with congenitally corrected transposition of the great arteries underwent anatomic repair. Thirty-one patients (group 1, mean age of $94.8 \pm 42.3$ months) underwent a combined Rastelli and atrial switch operation. Thirty-seven patients (group 2, mean age of $36.1 \pm 46.9$ months) underwent an arterial switch operation and atrial rerouting. Eight patients in group 2 had an intact ventricular septum.
\end{abstract}

Results: Group 1 had 5 early deaths $(17 \%)$ but no late deaths. Three patients underwent conduit revision at a mean follow-up of 62 months. Group 2 had 5 early deaths (13.5\%). There were 4 late reoperations ( 2 pulmonary baffle revisions, 1 mitral valve replacement, and 1 permanent pacemaker implantation) and 4 late deaths (1 secondary to progressive left ventricular dysfunction, 2 secondary to uncontrolled atrial tachyarrhythmia, and 1 secondary to pulmonary hypertension and right ventricular failure). In group 2, 4 patients have a left ventricular ejection fraction less than $40 \%, 5$ patients have moderate aortic incompetence, 5 patients have symptomatic tricuspid incompetence, 1 patient has tricuspid stenosis, 1 patient has superior cava obstruction, and 3 patients are receiving antiarrhythmic therapy.

Conclusion: The occurrence of left ventricular dysfunction indicate that anatomic repair in the arterial switch group is still fraught with imperfections. The Rastelli group required conduit revisions but has otherwise performed well.

Supplemental material is available online.

For many years, the conventional repair of lesions associated with congenitally corrected transposition of the great arteries (CCTGA), wherein the morphologic right ventricle (RV) remains the systemic pumping chamber, was the rule. ${ }^{1-3}$ However, long-term results of this strategy were found to be compromised by the progressive functional deterioration of the systemic RV and the progression of preexistent or development of new tricuspid valve (TV) incompetence. ${ }^{4-6}$

To overcome the disadvantages of conventional repair, the anatomic approach has gained popularity ${ }^{7-13}$ because it helps to achieve a systemic left ventricle (LV) and mitral valve (MV). Additional benefits of the approach are the

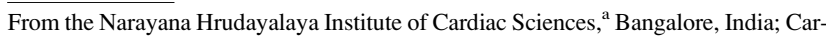
diothoracic Center, All India Institute of Medical Sciences, ${ }^{\mathrm{b}}$ New Delhi, India; and Fortis Hospital, ${ }^{\mathrm{c}}$ New Delhi, India.

Received for publication March 30, 2008; revisions received Aug 2, 2008; accepted for publication Sept 19, 2008.

Address for reprints: Rajesh Sharma, Director of Pediatric Cardiac Surgery, Escorts Heart Institute and Research Centre, New Delhi-110025, India (E-mail: rsharmacvs@hotmail.com).

J Thorac Cardiovasc Surg 2009; 137:404-12

$0022-5223 / \$ 36.00$

Copyright (c) 2009 by The American Association for Thoracic Surgery doi: $10.1016 /$ j.jtcvs. 2008.09 .048 removal of the dysfunctional RV and TV from the systemic circulation and placement in the low pressure pulmonary position. We reported our initial results with anatomic repair of CCTGA approximately a decade ago. ${ }^{14}$ As our experience has grown and the follow-up period has increased, we are now in a position to present the detailed results with a longer follow-up of the patients who underwent operation in the last 13 years.

\section{MATERIALS AND METHODS}

Between May 1994 and September 2007, 68 patients with CCTGA underwent anatomic repair by a single surgeon (R.S.) at 3 different centers: All India Institute of Medical Sciences, New Delhi, India (1994-2001), Narayana Hrudayalaya Institute of Cardiac sciences, Bangalore, India (20012007), and Fortis Hospital, New Delhi, India (2007). The preoperative evaluation, surgical techniques, and postoperative management protocols were the same in all patients. Detailed data of each patient were obtained from hospital records and analyzed. Follow-up was obtained from outpatient clinic records, communication from local cardiologists, or direct examination of the patients. The institutional review board waived the need for a formal ethical clearance because the study was retrospective and patient identity was not disclosed.

Of the 68 patients (Table 1), 31 had severe valvar pulmonic stenosis or pulmonary atresia (group 1) and underwent a Rastelli with atrial rerouting operation. ${ }^{15}$ The remaining 37 patients had a pulmonary valve that was usable in the aortic position (group 2) and underwent a combined arterial switch operation (ASO) and atrial switch procedure. ${ }^{7}$ Eight patients in group 2 had an intact ventricular septum. Four of these patients had pulmonary hypertension caused by a large patent ductus arteriosus $(n=1)$ or severe TV incompetence $(n=3)$, on the basis of which the LV was deemed 


$$
\begin{aligned}
& \text { Abbreviations and Acronyms } \\
& \text { AI }=\text { aortic incompetence } \\
& \text { ASO }=\text { arterial switch operation } \\
& \text { CCTGA }=\text { congenitally corrected transposition } \\
& \text { of the great arteries } \\
& \text { CPB }=\text { cardiopulmonary bypass } \\
& \text { CX }=\text { circumflex artery } \\
& \text { LCA }=\text { left coronary artery } \\
& \text { LV }=\text { left ventricle } \\
& \text { LVEF }=\text { left ventricular ejection fraction } \\
& \text { MPA }=\text { main pulmonary artery } \\
& \text { MV }=\text { mitral valve } \\
& \text { RA }=\text { right atrium } \\
& \text { RCA }=\text { right coronary artery } \\
& \text { RV }=\text { right ventricle } \\
& \text { TR }=\text { tricuspid regurgitation } \\
& \text { TV }=\text { tricuspid valve } \\
& \text { VSD }=\text { ventricular septal defect }
\end{aligned}
$$

"prepared." The remaining 4 patients underwent preliminary pulmonary artery banding for LV preparation before anatomic repair.

\section{Surgical Technique}

Routine cardiopulmonary bypass (CPB) with ascending aortic inflow and bicaval drainage with moderate hypothermia $\left(28^{\circ} \mathrm{C}\right)$ was used. Preexisting systemic to pulmonary artery shunts and major aortopulmonary collateral arteries were dissected before initiation of CPB and occluded. Antegrade hyperkalemic cold blood cardioplegia was delivered every 20 to 30 minutes via the ascending aorta or direct cannulation of the coronary artery ostia. Surgical procedures were fairly standard. The salient important features are summarized below.

\section{Atrial Switch}

In view of the not uncommon occurrence of apicocaval juxtaposition in CCTGA, the free wall of the right atrium (RA) may be unsuitable for a standard Senning operation. ${ }^{16}$ Certain modifications were therefore introduced to facilitate an atrial-level switch operation. Both the superior and inferior vena cavae were looped and cannulated extrapericardially to leave the pericardial reflection about the cavae and the pulmonary veins intact. This facilitated the use of in situ pericardium for construction of the pulmonary venous baffle. This technique has been described in detail. ${ }^{16-18}$ Most of the RA free wall was then used for constructing the systemic venous tunnel, directing both caval inflow into the morphologic TV.

The final step of the atrial switch operation, that is, the construction of the pulmonary venous baffle directing the pulmonary veins to the MV, was performed using in situ pericardium ${ }^{16-18}$ (Figure E1), often after release of the aortic clamp with the MV made incompetent with a frustrator to avoid air embolization when the heart started to beat. In our experience, this helps to avoid LV distension from any neoaortic incompetence (when the heart action is still sluggish) and to assess the degree of the same by direct examination through the MV.

\section{Closure of the Ventricular Septal Defect}

Group 1. In patients who underwent the Rastelli operation to connect the LV to the aorta, the ventricular septal defect (VSD) was first inspected after opening the RA to judge routability to the aorta. Once this was confirmed, the morphologic RV was opened between stay sutures in a portion
TABLE 1. Patient characteristics and anatomic associations of congenitally corrected transposition of the great arteries with ventricular septal defect and nonusable pulmonary valve (group 1) and pulmonary valve usable in the aortic position (group 2)

\begin{tabular}{lcc}
\hline \multicolumn{1}{c}{ Patient characteristics } & Group 1 & Group 2 \\
\hline Age (mo) & $94.8 \pm 42.3$ & $36.1 \pm 46.9$ \\
(range 24-192) & (range 3-216) \\
VSD & 31 & 28 \\
IDD & 8 & - \\
Pulmonary atresia & 15 & - \\
Pulmonary artery bifurcation stenosis & 17 & - \\
Single pulmonary artery & 1 & - \\
Bilateral SVC & 6 & 4 \\
TR & 4 & 11 \\
Previous BT shunt & 8 & - \\
MAPCA & 1 & - \\
DORV & 21 & 2 \\
Interrupted IVC & 1 & - \\
TAPVC to systemic atrium & 1 & 2 \\
Preexistent CHB & 1 & 2 \\
Cleft mitral leaflet and MR & - & 1 \\
Intramural LMCA & - & 1 \\
Bicuspid PV & - & 6 \\
Resectable subpulmonary obstruction & - & 4 \\
Large PDA & - & 1 \\
Ebstein TV & - & 5 \\
Criss-cross AV connection & & 2 \\
PA band* & - & $6 *$ \\
\hline VSD Veticur sepa deft & & \\
\hline
\end{tabular}

$V S D$, Ventricular septal defect; $I D D$, situs inversus with CCTGA; $P A$, pulmonary artery; $S V C$, superior vena cava; $T R$, tricuspid regurgitation; $B T$, Blalock-Taussig; $M A P C A$, major aortopulmonary collaterals; $C H B$, complete heart block; DORV, double outlet right ventricle; $I V C$, inferior vena cava; TAPVC, total anomalous pulmonary venous drainage; $A V$, atrioventricular; $T V$, tricuspid valve; $L M C A$, left main coronary artery; $P D A$, patent ductus arteriosus; $M R$, mitral regurgitation; $P V$, pulmonary valve. *Four for $\mathrm{LV}$ preparation and 2 done elsewhere for palliation of large VSD.

devoid of coronary arteries, and a tunnel of appropriate length and diameter was constructed between the LV and the aorta. In patients in whom the aorta was distant from the VSD, the tunnel was constructed in 2 halves with separate patches ${ }^{19}$ (Figure E2), one around the VSD edge and the other around the aortic annulus, both sutured together midway after judging the length of each that needed to be sacrificed to avoid redundancy and too tight a patch. It is important to form the inferior edge of the tunnel by suturing to the anterior TV annulus (and not valve leaflet) to prevent disruption.

Group 2. The VSD was closed through the morphologic MV via the RA. The VSD patch was placed on the leftward aspect of the septum toward the morphologic RV in the anterosuperior margin to avoid the superiorly located conduction bundle. ${ }^{20}$ Damage to the MV suspensory apparatus has to be avoided, because this would detract from one of the fundamental goals of this operation: to achieve a competent systemic AV junction. In 2 patients, the VSD was closed through the aortic valve, and in 1 patient with double outlet RV, where the aortic valve was too distant to reach though the $\mathrm{MV}$, the VSD required a combined approach via the RA, main pulmonary artery (MPA), and morphologic RV.

\section{Extracardiac Conduit Placement}

In group 1, the RV to pulmonary artery connection required the interposition of a valved conduit. The distal anastomosis between the conduit and the pulmonary artery was often performed after establishing CPB, before 
aortic crossclamping in those patients in whom the LV routability to the aorta via the VSD was not in doubt. The proximal anastomosis was made after release of the crossclamp on the beating heart, once the remainder of the intracardiac repair had been completed, using a pericardial extension. The conduits were placed to the right or left of the aorta and oriented in a fashion to minimize sternal compression. In all patients except 3 , an appropriately size cryopreserved homograft was used. In the remaining 3 patients, a porcine xenograft was used.

\section{Arterial Switch Operation}

The ASO was accomplished in the usual manner. Important differences compared with the standard ASO for dextro-transposition of the great arteries relate to the shorter length of the ascending aorta, discrepancy between the diameters of the ascending aorta and the MPA (larger than the aorta), and the typical coronary artery anatomy (Figure E3). In CCTGA, the anteriorly arising left coronary artery (LCA) supplies the morphologic $\mathrm{LV}$ and divides immediately after origin into the left anterior descending and left circumflex (CX) arteries. The anterior descending artery goes inferiorly toward the LV apex, whereas the CX lies on the anterior pulmonary annulus. The coronary artery that supplies the morphologic RV (referred to as the right coronary artery [RCA]) arises from the posterior aspect of the ascending aorta and faces anteriorly in opposite direction to posterior MPA. The short length of the aorta was addressed by cannulating the ascending aorta at the base of the innominate artery or in the arch. After the coronary artery buttons were harvested, the defects created by coronary button excision were filled up by a pantaloon-shaped patch of autologous untreated pericardium that was sutured in place before coronary implantation was begun. The MPA was transected as distally as possible, so that coronary implantation could be supracommissural. Even then, the lower level of the pulmonary artery compared with the ascending aorta may have a tendency to leave laxity in the RCA. To combat this, the RCA button was implanted at the left posterolateral aspect of the distal aortic-proximal MPA (now the neoaorta) anastomosis (often using a trapdoor flap). This redundancy of the neoaorta was addressed by forming a "keel" on its rightward aspect. This had the effect of elevating the posteriorly placed proximal neoaorta so that the LCA button could be implanted within the cul de sac of the neoaorta formed by the keel to achieve a tension-free direct anastomosis. The exact position of the LCA button was determined by distending the neoaortic root with a dose of cardioplegia infused into the reconstituted neoaorta bearing the RCA. The main points to be noted are to avoid kinking the redundant $\mathrm{CX}$ and overly stretching the anterior descending artery. Finally, the Lecompte maneuver was performed in all patients except 1 adult in whom an interposition graft was placed between the proximal neopulmonary artery annulus and the distal pulmonary artery bifurcation. Anterior LCA compression was avoided by shifting the distal pulmonary artery anastomosis leftward on the pulmonary artery bifurcation because of the leftward position of the neopulmonary artery stump.

One patient with a single coronary ostium and an intramural left main coronary artery was managed by conversion to a 2-coronary system by unroofing the length of the intramural LCA, thereby shifting the right-sided left coronary ostium laterally and allowing splitting of the single button into 2, each bearing the individual ostia.

Associated procedures included TV annuloplasty in 10 patients with severe tricuspid regurgitation (TR) along with tricuspid leaflet cleft closure in 2 patients. One patient required closure of the MV cleft because of mitral regurgitation. A bidirectional Glenn anastomosis was constructed in 2 patients in group 1 to reduce the complexity of the atrial part of the repair, but this procedure was subsequently abandoned after 1 patient died as the result of malignant superior vena cava syndrome secondary to elevated pulmonary artery pressures in the postoperative period. Postoperative inotropic support consisted of dobutamine, milrinone, and ventilatory support until the cardiac output was judged to be optimal. Because of bleeding, the sternum was left open in 5 patients in group 2 and zero patients in group 1.
All patients had transthoracic echocardiographic examinations in the postoperative period for assessment of adequacy of repair, LV and RV function, and mitral regurgitation or TR, and to indirectly estimate pulmonary artery pressures because no pulmonary arterial pressure monitoring lines were placed.

\section{Follow-Up and Statistical Analysis}

After discharge, patients were followed up at 1 month and 3 months, and then at 6-month intervals. At each visit, patients underwent clinical examination, electrocardiograms, and detailed echocardiograms. Between July and December of 2007 (closing interval), all follow-up data were analyzed to report the results. Follow-up was $100 \%$ complete and was a mean of $62.03 \pm 48.24$ months (1-156 months) in group 1 and $51.9 \pm 45.1$ months (range 1-162 months) in group 2.

Data were analyzed using the Statistical Package for the Social Sciences for Windows 11.5 (SPSS Inc, Chicago, Ill). Descriptive statistics (ie, mean and standard deviations) have been calculated for continuous variables, and simple percentages are presented wherever applicable. Actuarial estimates were calculated using the Kaplan-Meier analysis. For analysis, an event was described as any early or late death; reoperation; ventricular dysfunction (left ventricular ejection fraction $[\mathrm{LVEF}]<40 \%$ ); mitral regurgitation, aortic regurgitation, or TR (moderate or severe); or arrhythmias. Chi-square tests were performed to discern significant associations between group and other risk factors.

\section{RESULTS \\ Early Results}

Group $1(\mathbf{n}=\mathbf{3 1})$. The median CPB time was 205 minutes, and the median aortic crossclamp time was 145 minutes. There were 5 early deaths (17\%): 1) Sepsis occurred in 1 patient after an early reoperation for disruption of the caval baffle of the Senning part of the repair on the third postoperative day. 2) One patient who had undergone 1-stage unifocalization of large hypertensive major aortopulmonary collateral arteries, along with a Senning and Rastelli repair from the midline, failed to demonstrate any regression in pulmonary artery pressures from the systemic level and died secondary to right-sided heart failure. 3) Massive delayed superior vena cava syndrome occurred in a child who had undergone a bidirectional Glenn anastomosis along with a Rastelli and an inferior cava to tricuspid baffle. This was revealed by postoperative cardiac catheterization to be due to worsening LV function and secondary pulmonary artery pressure elevation without any anatomic residua. 4) Uncontrolled pulmonary hemorrhage with no demonstrable residua or aortopulmonary communications of any significance occurred in 1 patient. 5) Severe LV dysfunction with new-onset mitral regurgitation in a background of borderline LV size occurred in 1 patient.

The mean intensive care unit stay was 15 days (range 735 days). Sixteen patients required prolonged pleural drainage for pleural effusions that were finally self-limited in all. Four patients required implantation of permanent pacemaker for surgically induced complete heart block.

Three patients underwent reoperation at a mean postoperative period of 3 weeks for disruption of VSD patch suture line. All of these patients had a remote non-overriding aorta 
distant from the plane of the VSD. The site of disruption in all was the tricuspid annulus. As mentioned above, we modified our technique of VSD closure and used multiple patches more frequently in the latter part of our experience to overcome this problem. As detailed above, another patient required reoperation for disruption of the caval baffle of the Senning part of the repair on the third postoperative day.

Two patients required aortopulmonary collateral embolization for pulmonary hemorrhage while on a ventilator after the Rastelli-Senning operation.

One patient with CCTGA VSD and pulmonary atresia with situs inversus with CCTGA had difficulty being weaned from the ventilator because of repeated near-death episodes secondary to casts of the entire bronchial tree causing sudden complete airway obstruction (plastic bronchitis). The problem was resolved with delivery of nebulized urokinase ${ }^{21}$ via a tracheostomy mask. The patient was discharged with the advice to continue these nebulizations indefinitely. (Cardiac catheterization failed to reveal any residual defect that could account for this complication, and the cause was therefore attributed to her single lung status.)

Group $2(\mathbf{n}=\mathbf{3 7})$. The median CPB time was 240 minutes, and the median aortic crossclamp time was 180 minutes. There were 5 early deaths $(13.5 \%)$. Two deaths were secondary to pulmonary hypertensive crises, 2 deaths were secondary to progressive pulmonary consolidation that led to failure of gas exchange, and 1 death was secondary to an unprepared LV in a 3-month-old patient with CCTGA, an intact ventricular septum, and $60 \%$ systemic LV pressure who underwent 1-stage anatomic repair.

In all patients, echocardiography after transfer to the intensive care unit (currently, we perform transesophageal echocardiography in the operating room) showed an RV with diminished volume and an LV with compensatory dilatation. Serial echocardiograms showed return of the $\mathrm{LV}$ to smaller volumes. The reduction in RV pressure and volume was accompanied by a reduction in TR pressure gradient and severity. The persistence of TR, albeit low pressure, in a morphologically abnormal TV necessitated a concomitant TV repair in 10 children. The mean intensive care unit stay was 16 days (range 4-42 days).

Seven children required prolonged mechanical ventilation secondary to suboptimal arterial blood gases with no discernible cause $(\mathrm{n}=3)$, persistent elevation of pulmonary artery pressures $(\mathrm{n}=1)$, unprepared LV $(\mathrm{n}=1)$, and significant $\mathrm{LV}$ dysfunction $(\mathrm{LVEF}<40 \%)(\mathrm{n}=2)$. Three of these patients required tracheostomy for excessive pulmonary secretions before they could be weaned from mechanical ventilatory support.

Complete heart block developed in 6 patients, necessitating permanent pacemaker insertion before discharge. Two patients required hospitalization in excess of 2 months for completion of antibiotic treatment for infective endocarditis of the VSD patch.

\section{Follow-up}

Follow-up was a mean of $54.6 \pm 45.7$ months (1-162 months, median 58.5 months). Of the 58 survivors, 12 were followed up for 10 years or more, 27 were followed up for 5 years or more, and 44 were followed up for 3 years or more.

Four late deaths occurred in group 2. Two late deaths 2 and 3 years after the initial operation were secondary to uncontrolled atrial tachyarrhythmia. Both patients had loss of sinus rhythm immediately after surgery, probably caused by the atrial switch component of the repair. Another death occurred secondary to progressive LV dysfunction in a 3year-old boy. This child had also sustained complete heart block at surgery with subsequent permanent pacemaker implantation. The fourth death was in a 2-year-old child with CCTGA, an intact ventricular septum, and severe pulmonary hypertension secondary to TR. Good early outcome was followed by late demise secondary to severe persistent pulmonary arterial hypertension and RV failure.

\section{Reoperation}

In group 1, 3 patients have thus far undergone revision of their conduits, all by conversion to an outflow patch, in an effort to make the RV outflow relatively low profiled to minimize chest wall compression and future reoperations.

In group 2, 3 patients underwent reoperation. One MV replacement was performed 4 years after the primary operation because of MV chordal injury sustained during VSD closure.

Pulmonary venous obstruction developed in 2 patients, one of whom had stenosis of the Senning pathway and one of whom outgrew the pulmonary venous baffle. In the latter patient, a patch covering the pulmonary venous opening and MV had been constructed to direct pulmonary venous return to the morphologic LV with total anomalous pulmonary venous drainage to the RA. Both of these patients required revision of their pulmonary venous baffles.

\section{Rhythm Disturbances}

One patient in group 1 had recurrent syncope resulting from tachyarrhythmia from a preexcitation pathway after conduit revision. Because the condition was poorly controlled with drugs, the patient underwent successful transcatheter radiofrequency ablation of the bypass tract. In group 2, new heart block developed in 1 child 2 years after surgery, and a permanent pacemaker was implanted. In group 2, 1 patient is receiving beta-blockers for treatment of recurrent atriatachycardia, and 2 patients are receiving amiodarone. 


\section{Functional Outcome: Ventricular Function in Survivors}

Patients who survived the postoperative period in group 2 have had no significant issues and continue to do well with normal biventricular function. Four patients have significant LV dysfunction ( $\mathrm{LVEF}<40 \%$ ) and are receiving angiotensin-converting enzyme inhibitors. All have undergone cardiac catheterization and angiography, which revealed patent coronary arteries in all. Three of the patients are in sinus rhythm, and 1 patient had congenital complete heart block and a pacemaker implanted. No cause has been found for the development of LV dysfunction in these patients. Intraoperative ischemic times in these patients were no different than in the other patients. Four other survivors have an LVEF ranging from $45 \%$ to $50 \%$.The LV function of the remainder of the group is normal.

\section{Aortic Incompetence}

Five survivors in group 2 have moderate aortic incompetence (AI), 3 of whom had preexistent pulmonary regurgitation secondary to severe pulmonary hypertension and dilatation of the pulmonary root. The remaining 2 patients had prior pulmonary artery banding for $\mathrm{LV}$ preparation.

\section{Aortic Valve Gradients}

In group 2, 5 patients with bicuspid pulmonary valves and preoperative gradients ranging from 30 to $70 \mathrm{~mm} \mathrm{Hg}$ in the presence of a VSD now have gradients of 25 and $30 \mathrm{~mm} \mathrm{Hg}$ (across the neoaortic valve in 2 patients).

\section{Tricuspid Valve Residua}

Five patients in group 2 have moderate residual TR in the setting of an Ebstein's malformation of the tricuspid anatomy. One child has a tricuspid gradient of $4 \mathrm{~mm} \mathrm{Hg}$ caused by tricuspid hypoplasia and had prolonged chylous effusions in the early postoperative period. All children with residual tricuspid issues require diuretic therapy to prevent clinical fluid retention.

\section{Miscellaneous Issues}

There was an expected progression of gradients across the right-sided conduits in patients in group 1. One child in group 2 was found to have superior cava obstruction at the 2-year follow-up. Because he has no symptoms (secondary to a decompressing azygous vein), appropriate treatment is still undecided.

\section{Congenitally Corrected Transposition of the Great Arteries with Intact Interventricular Septum}

Eight children with CCTGA and an intact ventricular septum were scheduled for anatomic repair because of severe TR in all. Four patients had pulmonary hypertension.
Pulmonary hypertension was secondary to a large ductus arteriosus in 1 patient and to back pressure from RV dysfunction and TR in 3 patients. Systemic pulmonary artery pressures were present in 3 patients, and pulmonary artery pressure was $60 \%$ of the systemic arterial pressure in 1 patient. The patient with $60 \%$ pulmonary artery pressure died of LV failure after surgery. Those with systemic pulmonary artery pressure had good early survival, but one patient died of severe right-sided heart failure as the result of non-subsidence of pulmonary artery pressures 8 months after surgery. Severe LV dysfunction with patent coronaries developed in the patient with a large ductus arteriosus, which is being treated with medical therapy.

The other 4 patients had regressed LV mass and underwent preparatory pulmonary artery banding for LV training. Their ages ranged from 4 months to 9 years (mean 5 years). After a mean interval of 16 months (range 9 months to 2 years), they underwent cardiac catheterization to confirm LV pressures followed by the ASO and Senning with removal of the pulmonary artery band. All patients survived the surgery and have a mean LVEF of $50 \%$ (range $45 \%-$ $55 \%$ ) on a mean follow-up of 9 months (range 2-18 months). All patients have no more than mild AI and only mild TR.

At 5 years of follow-up, the actuarial survival for the entire group of all patients in this study was $80.5 \% \pm 4.9 \%$, the reoperation-free survival was $84.7 \% \pm 6.6 \%$, and the event-free survival was $65.4 \% \pm 6.8 \%$ (Figures $1-3$ ). The actuarial, reoperation-free, and event-free survivals were $83.9 \% \pm 6.7 \%, 85.7 \% \pm 9.3 \%$, and $71.9 \% \pm 9.7 \%$ in group 1 and $77.7 \% \pm 7 \%, 85.6 \% \pm 7.9 \%$, and $59.8 \% \pm$ $8.8 \%$ in group 2 , respectively. There were no differences in these figures between the 2 groups. In a detailed analysis of the events in these patients, it was found that there was a significantly higher incidence of LV dysfunction postoperatively in patients who underwent a combined Senning and ASO (likelihood ratio $7.8, P=.005$ ). There were no specific predictors of early or late death or of actuarial, reoperationfree, and event-free survival in the 68 patients.

\section{DISCUSSION}

The principle disadvantage of the classic approach to repair of CCTGA with associated lesions is that it leaves the morphologic RV supporting the systemic circulation. As a consequence, the finding of late systemic ventricular failure is not uncommon after this approach. ${ }^{4-6}$ The heralding of anatomic repair of CCTGA was therefore a veritable panacea for this lesion because it eliminates the issue of the systemic RV. ${ }^{7-14}$

The discovery of significant LV dysfunction in a definite proportion of patients with CCTGA who have undergone anatomic repair by the combined Senning and ASO is therefore a distressing finding. ${ }^{12,17,22,23}$ In these patients, we are actually ending up with the same problem that we set out 


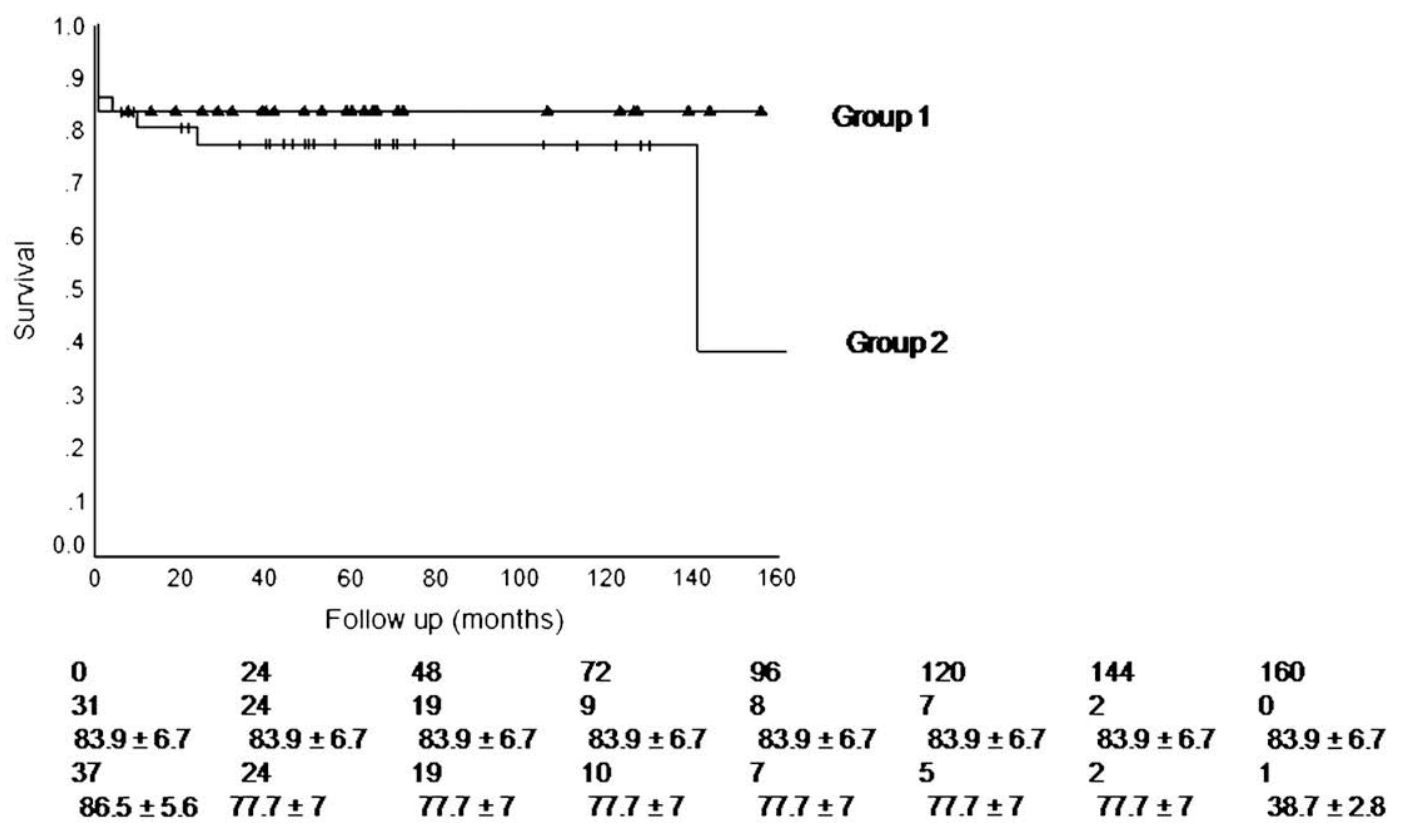

Time (months)

At Risk (group1)

Survival (group1)

At Risk (group 2)

Survival (group 2)

FIGURE 1. Actuarial survival in patients undergoing the double switch operation.

to prevent, sometimes in an even more accelerated manner than after classic repair. In our own experience, there have been 5 children with postoperative LVEF less than $40 \%$. One whose LVEF progressively decreased to $10 \%$ to $15 \%$ less than 1 year after the double switch operation died 14 months after operation. All children in this group have undergone cardiac catheterization and angiography to ascertain the cause. Unobstructed coronary arteries were demonstrated in all. There was no LV outflow gradient in any of the patients. LV dysfunction has also been noticed by other groups ${ }^{12,17,22,23}$ and has been variously attributed to coexistent complete heart block ${ }^{12,22}$ or development of neoaortic regurgitation. ${ }^{18}$ Even the development of arrhythmias and the need for pacemaker implantation have been reported to be major causes of systemic ventricular dysfunction in unoperated patients with CCTGA. ${ }^{24}$ In our series,
Time (months)

At Risk (group1)

Survival (group1)

At Risk (group 2)

Survival (group 2)

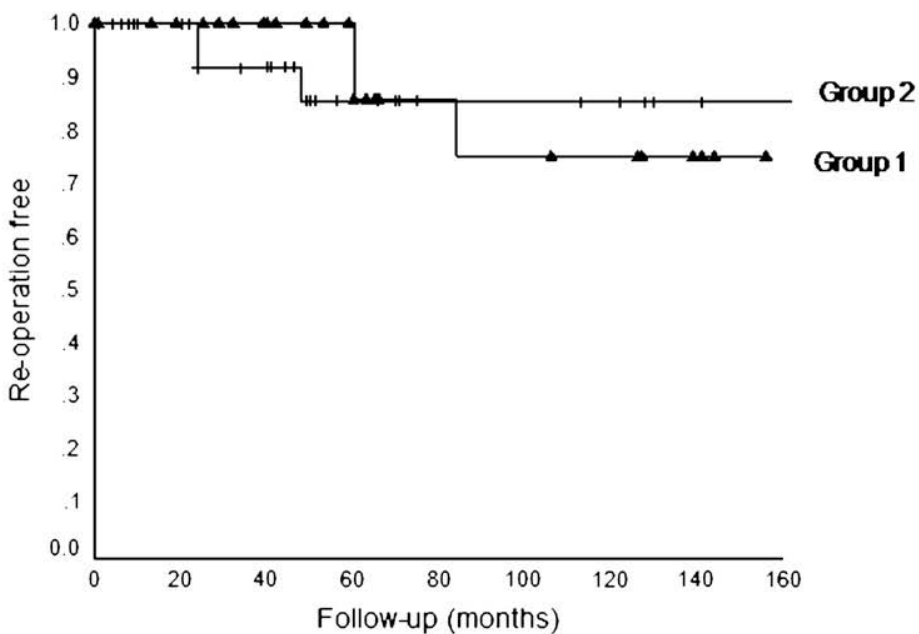

$\begin{array}{llllllll}0 & 24 & 48 & 72 & 96 & 120 & 144 & 160 \\ 31 & 24 & 18 & 9 & 7 & 6 & 2 & 0 \\ 100 & 100 & 100 & 85.7 \pm 9.3 & 75 \pm 12 & 75 \pm 12 & 75 \pm 12 & 75 \pm 12 \\ 37 & 23 & 14 & 7 & 6 & 5 & 1 & 0\end{array}$

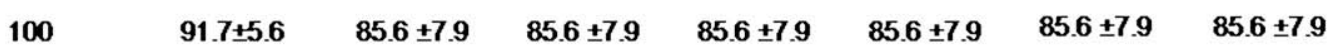

FIGURE 2. Reoperation-free survival in patients undergoing the double switch operation. 


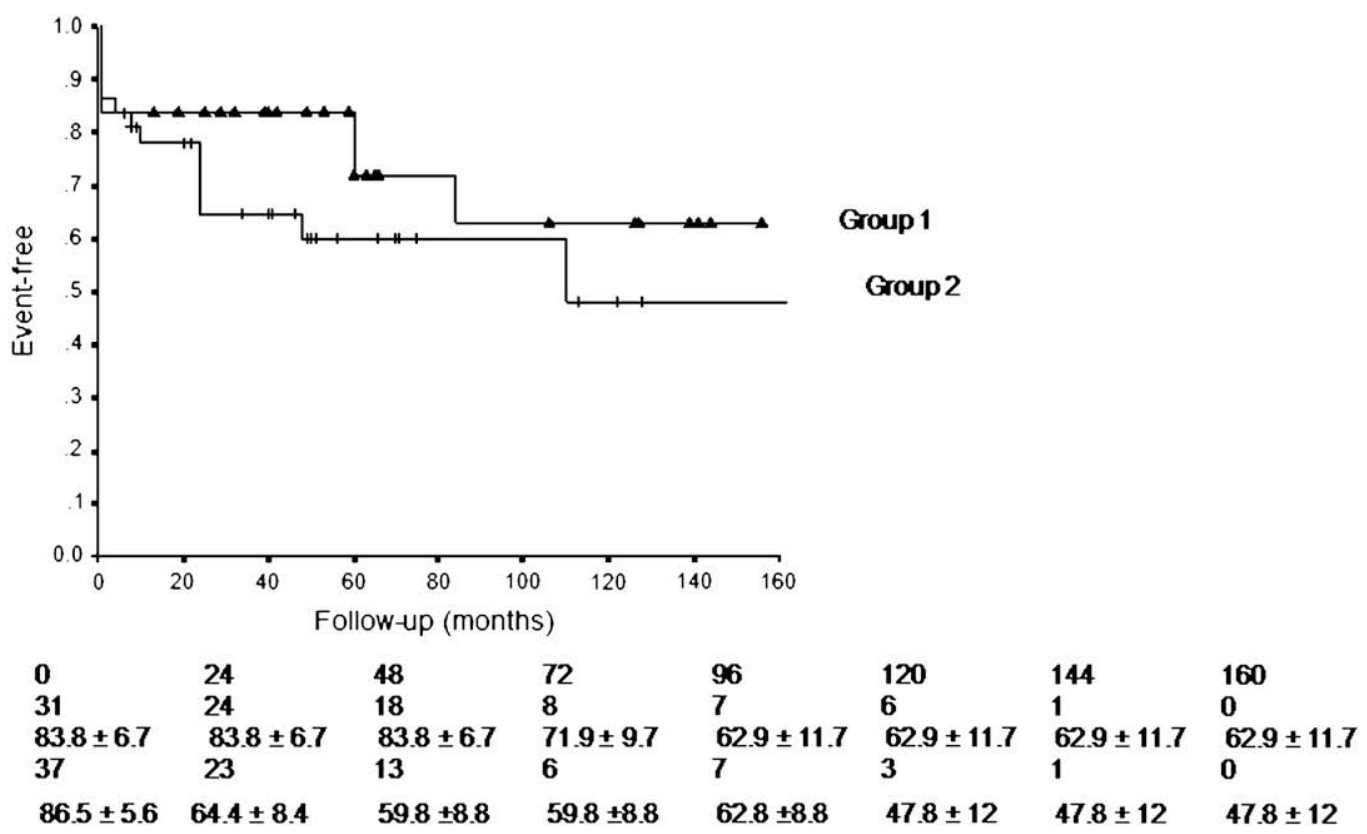

FIGURE 3. Event-free survival in patients undergoing the double switch operation.

only 2 of the children with LV dysfunction have complete heart block (although these 2 patients are the most seriously affected), whereas the others are in sinus rhythm. Significant AI could be another factor contributing to $\mathrm{LV}$ dysfunction. ${ }^{18}$ In the group of patients with an LVEF less than $40 \%, 2$ have moderate AI. Three patients with equivalent degrees of AI have an LVEF greater than $50 \%$. Thus, we need to look beyond these 2 factors for the real reason behind the LV dysfunction after the double switch operation. One of the associations in our series was between the existence of large left to right shunts in all those who had an LVEF of $40 \%$ (1 large patent ductus arteriosus and VSD in the others). Although the number is small and not comparable, LV function in patients who did not have a large left to right shunt preoperatively seems to be better than in the group who had a large VSD or patent ductus arteriosus as a cause of LV preparedness.

It has been our observation that echocardiograms immediately after completion of ASO+Senning + VSD closure and elimination of large ductus arteriosus have shown an RV with diminished volume and an LV with compensatory dilatation as it takes up its new role of systemic afterload support. Serial echocardiograms showed return of the LV to smaller volumes. With time, the degree to which the LV volumes and systolic function return to normal is the factor that determines the final ventricular function. Notably, all patients with "LV dysfunction" are completely asymptomatic, and if the single death that occurred in the child with extreme diminution of LV systolic function is ignored, LV dysfunction may remain unsuspected until an echocardiogram is performed. To the contrary, preoperatively dilated $\mathrm{RVs}$ indicative of RV dysfunction invariably decreased dimensions drastically, commensurate with a decrease in pulmonary artery pressures, except in those in whom the $\mathrm{RV}$ pressure remained elevated. This coincided with a drastic reduction or disappearance of TR.

The long ischemic time to which the heart is subjected while the operation is in progress may also be an important causative factor contributing to LV dysfunction. Strategies to optimize myocardial preservation would address this important issue.

\section{Aortic Incompetence}

$\mathrm{AI}$ is a not an infrequent finding after the ASO and Senning operation. The various factors that may be implicated are as follows: 1) Preexistent pulmonary regurgitation that is converted to neoaortic valve leakage. 2) A dilated neoaortic root in the setting of CCTGA, VSD, and pulmonary arterial hypertension needs to be connected to the diminutive distal aorta, and the acute change in diameter of the newly constructed aorta may result in sinotubular distortion. 3) Great artery relationship in CCTGA is most often side by side, and coronary transfer is never as straightforward as in DTGA. The violation of the sinotubular junction by incisions to fit the coronary buttons in the neoaortic root may also contribute to neoaortic incompetence. 4) Long-standing preexistent pulmonary artery band may also predispose a patient to AI. None of our patients who underwent banding earlier had any more than mild AI.

\section{Mitral Regurgitation}

Inadvertant injury to the MV during VSD closure is to be strictly guarded against. The price that had to be paid for avulsion of a single chorda in one of our patients was a later 
valve replacement because the apicocaval juxtaposition made any assessment of mitral pathology or intraoperative assessment of attempted repair impossible at reoperation.

\section{Tricuspid Valve Pathology}

The abnormal Ebstein malformation of the TV does not submit easily to repair, and even low pressure TR can be symptomatic, especially if the $\mathrm{RV}$ pressure remains elevated.

\section{Complete Heart Block}

The Rastelli and Senning option should be relatively immune to surgically induced complete heart block because the VSD suture line stays completely on the RV aspect of the interventricular septum. However, 4 patients had surgically induced complete heart block. The other area where the conduction tissue could be at jeopardy is the area of the accessory AV node in CCTGA and where the Senning suture line might expose it to risk of injury. In the Senning + ASO group, 6 patients required permanent pacemaker insertion. This was despite the fact that conscious effort was made to stay on the rightward aspect of the interventricular septum in the anterosuperior part of the VSD suture line where the conduction bundle is known to course on the LV aspect of the septum. ${ }^{20}$

\section{Intraventricular Tunnel in Rastelli and Senning with Distant Aorta}

The VSD in CCTGA VSD pulmonary stenosis with a remotely situated aorta makes the VSD almost noncommitted. In these cases, we have realized that a tunnel made of a single piece of patch is prone to incorrect sizing and thus postoperative patch dehiscence. In these patients, it is now our routine practice to construct the tunnel by joining 2 patches: one sutured around the VSD margin and one sutured around the aortic annulus. ${ }^{19}$ Three of our patients required early reoperation for dehiscence of the patch at the TV annulus. Since our adoption of this modification, this complication has not occurred.

In the presence of good Fontan criteria, the backout option of a Fontan was considered in patients in group 1 if the aorta was remote from the LV. If, however, the pulmonary artery anatomy was suboptimal or the pulmonary artery pressures were deemed to be elevated, there was little option but to choose a difficult intraventricular tunnel even with a remote aorta. This is achievable using the 2-patch modification that we have adopted in the recent past.

\section{Caveats}

Of the 5 early deaths in group 1, 1 patient each died of sepsis, nonregression of pulmonary artery pressures, superior vena cava syndrome, uncontrolled pulmonary hemorrhage, and severe LV dysfunction caused by borderline LV size. Except for the patient with sepsis and pulmonary hemorrhage, the other patients were probably poor candi- dates for anatomic repair and may have had a negative impact on the interpretation of the results of anatomic repair in this subset. Similarly, in group 2, of the 5 early deaths, 2 were due to pulmonary hypertensive crisis and one was due to an unprepared LV. It may seem that if one were to exclude these patients in both the groups, the results would be better; however, the important finding of significant new-onset ventricular dysfunction in patients in group 2 is still important because these patients were thought to be ideal candidates for this procedure. Finally, Senning-related complications (eg, baffle obstructions and arrhythmias) seemed to be more frequent in group 2 for unknown reasons despite the same surgical techniques in all patients, making interpretation of true results in this group difficult. It is still unpredictable as to which patients would have a good result with anatomic repair. The choice of operation is therefore easier if there is a clear-cut reason to believe that alternative treatment options would not show a better result (TR in either group or poor pulmonary artery anatomy and elevated pulmonary artery pressures in group 1).

\section{CONCLUSIONS}

The combined Rastelli and Senning option for CCTGA VSD pulmonary stenosis is a suitable biventricular option for those patients who do not have a usable pulmonary valve. Few late issues, other than progressive conduit gradients, have been observed in this group. The finding of LV dysfunction and issues related to new or residual valvular (aortic or tricuspid) incompetence and arrhythmias, which were also seen in the group undergoing combined atrial and ASO, prevents us from labeling this treatment option, as it stands today, as the ideal management option for this group of patients.

The authors thank Rajvir Singh, PhD (Biostatistics), for statistical analysis and T. K. Susheel Kumar for Figures E1 to E4.

\section{References}

1. Termingnon JL, Leca F, Vouhe PR, et al. Classic" repair of congenitally corrected transposition and ventricular septal defect. Ann Thorac Surg. 1996;62: 199-206.

2. Biliciler-Denktas G, Feldt RH, Connoly HM, Weaver AL, Puga FL, Danielson GK. Early and late results of operations for defects associated with corrected transposition and other anomalies with atrioventricular discordance in a pediatric population. J Thorac Cardiovasc Surg. 2001;122:234-41.

3. Rutledge JM, Nihill MR, Fraser CD, Smith OE, McMohan CJ, Bezold LI. Outcome of 121 patients with congenitally corrected transposition of the great arteries. Pediatr Cardiol. 2002;3:137-45.

4. Prieto LR, Hordof AJ, Secic M, et al. Progressive tricuspid valve disease in patients with congenitally corrected transposition of the great arteries. Circulation. 1998;98:997-1005.

5. Sano T, Riesenfeld T, Karl TR, et al. Intermediate-term outcome after intracardiac repair of associated cardiac defects in patients with atrioventricular and ventriculoarterial discordance. Circulation. 1995;82(suppl):SII-272-8.

6. Connelly MS, Liu PP, Williams WG, et al. Congenitally corrected transposition of the great arteries in the adult: functional status and implications. I Am Coll Cardiol. 1996;27:1238-43.

7. Yamagishi M, Imai Y. Hoshino, et al. Anatomic correction of atrioventricular discordance. J Thorac Cardiovasc Surg. 1993;105:1067-76. 
8. Imamura M, Drummond-Webb JJ, Murphy DJ Jr, et al. Results of the double switch operation in the current era. Ann Thorac Surg. 2000;70:100-5.

9. Ibawi MN, Ocampo CB, Allen BS, et al. Intermediate results of the anatomic repair for congenitally corrected transposition. Ann Thorac Surg. 2002;73:594-9.

10. Shin'oka T, Kurosawa H, Imai Y, et al. Outcomes of definitive surgical repair for congenitally corrected transposition of the great arteries or double outlet right ventricle with discordant atrioventricular connections: risk analyses in 189 patients. J Thorac Cardiovasc Surg. 2007;133:1318-28.

11. Duncan BW, Mee RB, Mesia CI, et al. Results of the double switch operation for congenitally corrected transposition of the great arteries. Eur J Cardiothorac Surg. 2003;24:11-9.

12. Langley SM, Winlaw DS, Stumper O, et al. Midterm results after restoration of the morphologically left ventricle to the systemic circulation in patients with congenitally corrected transposition of the great arteries. J Thorac Cardiovasc Surg. 2003; 125:1229-41.

13. Devaney EJ, Charpie JR, Ohye RG, Bove EL. Combined arterial switch and Senning operation for congenitally corrected transposition of the great arteries: patient selection and intermediate results. J Thorac Cardiovasc Surg. 2003;125:500-7.

14. Sharma R, Bhan A, Juneja R, Kothari SS, Saxena A, Venugopal P. Double switch for congenitally corrected transposition of the great arteries. Eur J Cardiothorac Surg. 1999;15:276-81.

15. Ibawi MN, DeLeon SY, Backer CL, et al. An alternative approach to the surgical management of physiologically corrected transposition with ventricular defect and pulmonary stenosis or atresia. J Thorac Cardiovasc Surg. 1990;100:410-5.

16. Kouchoukos NT, Blackstone EH, Doty DB, Hanley FH, Karp RH. Congenitally corrected transposition of the great arteries and other forms of atrioventricular discordant connection. In: Kirklin JW, Barrett-Boyes BG, eds. Cardiac Surgery: Morphology, Diagnostic Criteria, Natural History, Techniques, Results, and Indications. 3rd ed. Philadelphia, PA: Churchill Livingstone; 2003:1549-84.

17. Brawn WJ, Barron DJ. Technical aspects of the Rastelli and atrial switch procedure for congenitally corrected transposition of great arteries with ventricular septal defect and pulmonary stenosis or atresia: result of therapy. Semin Thorac Cardiovasc Surg Pediatr Card Surg Annu. 2003;6:4-8.

18. Brawn WJ. The double switch operation for atrioventricular discordance. Semin Thorac Cardiovasc Surg Pediatr Card Surg Annu. 2005;8:51-6.

19. Barbero-Marcial M, Tanamati C, Atik E, Ebaid M. Intraventricular repair of double outlet right ventricle with non-committed ventricular septal defect: advantages of multiple patches. J Thorac Cardiovasc Surg. 1999;118:1056-67.

20. Bharati S, Lev M, Kirklin JW. Cardiac Surgery and the Conduction System. 2nd ed. Mount Kisco, NY: Futura; 1992.

21. Quasney MW, Orman K, Thompson J, et al. Plastic bronchitis occurring late after the Fontan procedure: treatment with aerosolized urokinae. Crit Care Med. 2000; 28:2107-11.

22. Bautista-Hernandez V, Marx GR, Gauvreau K, et al. Determinants of left ventricular dysfunction after anatomic repair of congenitally corrected transposition of great arteries. Ann Thorac Surg. 2006;82:2059-66.

23. Yagihara T, Kishimoto H, Isobe F, et al. Double switch operation in cardiac anomalies with atrioventricular and ventriculoarterial discordance. J Thorac Cardiovasc Surg. 1994;107:351-8.

24. Graham TP Jr, Bernard YD, Mellen BG, et al. Long-term outcome in congenitally corrected transposition of the great arteries: a multi-institutional study. J Am Coll Cardiol. 2000;36:255-61. 


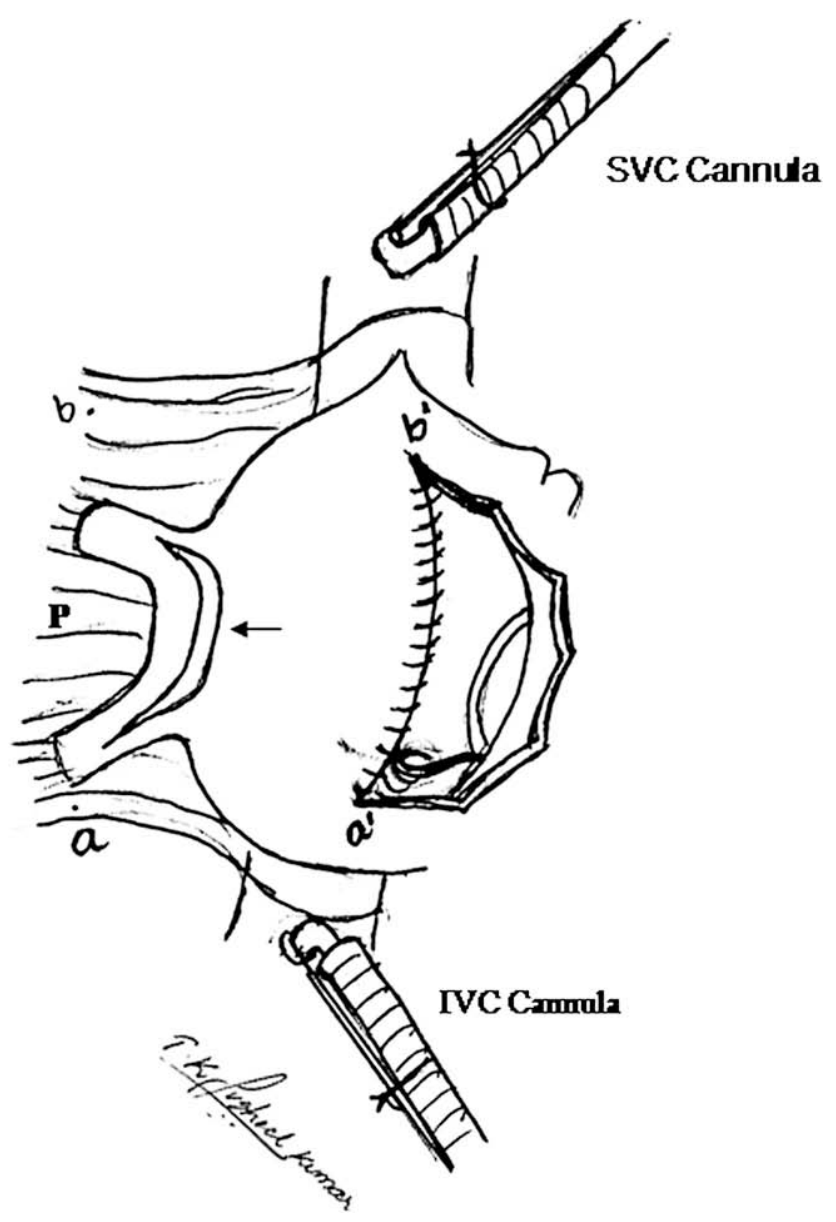

FIGURE E1. Technique of Senning operation using in situ pericardium. Points $b$ and $a$ on the free edge of the intact pericardial reflection $(\mathrm{P})$ are approximated to points b' and a' on the anterior lip of the right atriotomy incision. Opening in right pulmonary veins (arrow). $S V C$, Superior vena cava; $I V C$, inferior vena cava. 


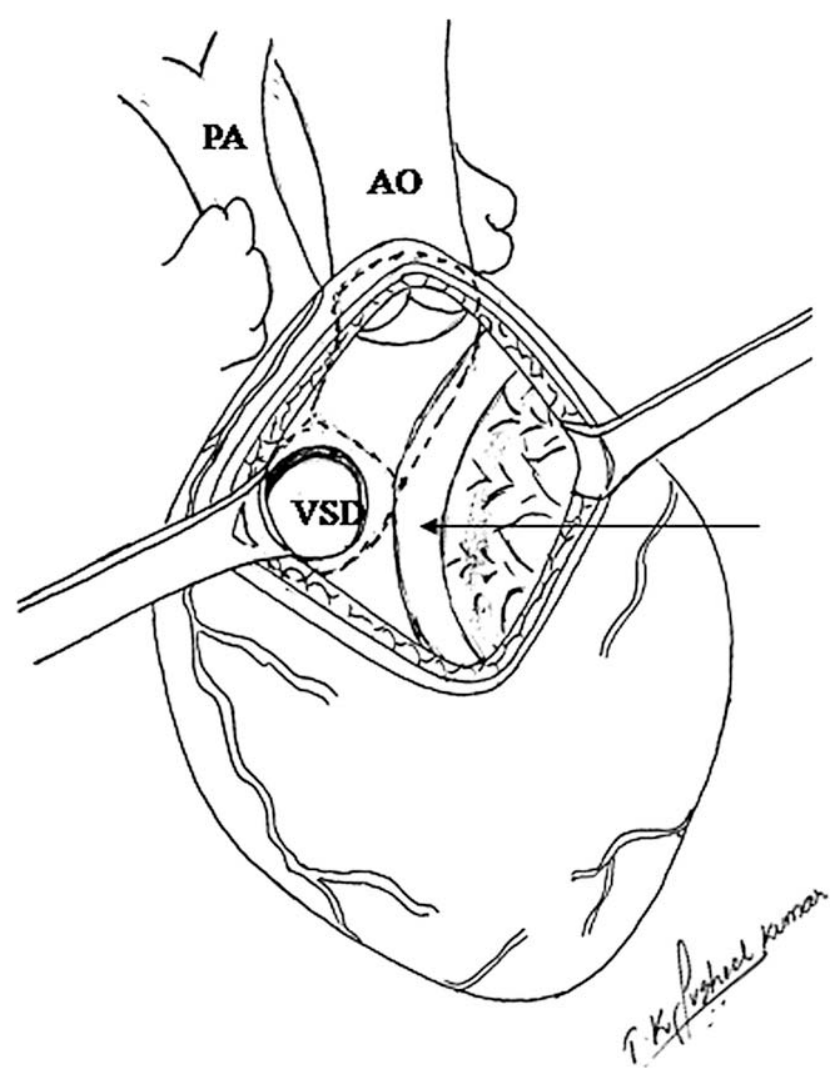

FIGURE E2. Through a right ventriculotomy, two patches are sutured, one around the VSD edge and the other around the aortic annulus, both sutured together midway. It is important to form the inferior edge of the tunnel by suturing to the anterior tricuspid valve annulus (arrow), and not valve leaflet, to prevent disruption. $A O$, Aorta; $T V$, tricuspid valve; $P A$, pulmonary artery. 


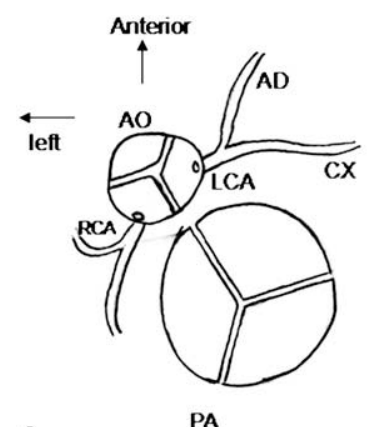

A

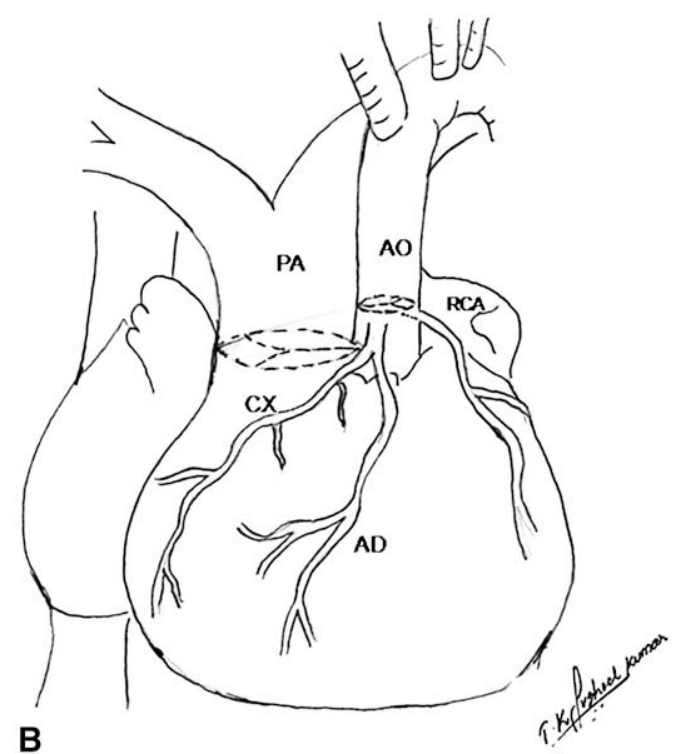

FIGURE E3. Coronary artery anatomy in CCTGA with relative positions of aortic and pulmonary roots. (A) Schematic drawing of coronary artery origin; (B) distribution of coronary arteries. Note the discrepancy between the size of the aorta $(A O)$ and the pulmonary artery $(P A)$. For details see text. $L C A$, Left coronary artery, $R C A$, right coronary artery; $A D$, anterior descending, $C X$, circumflex. 


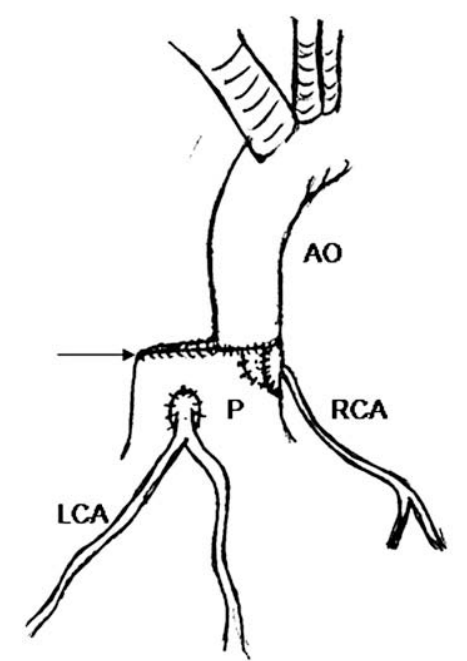

A

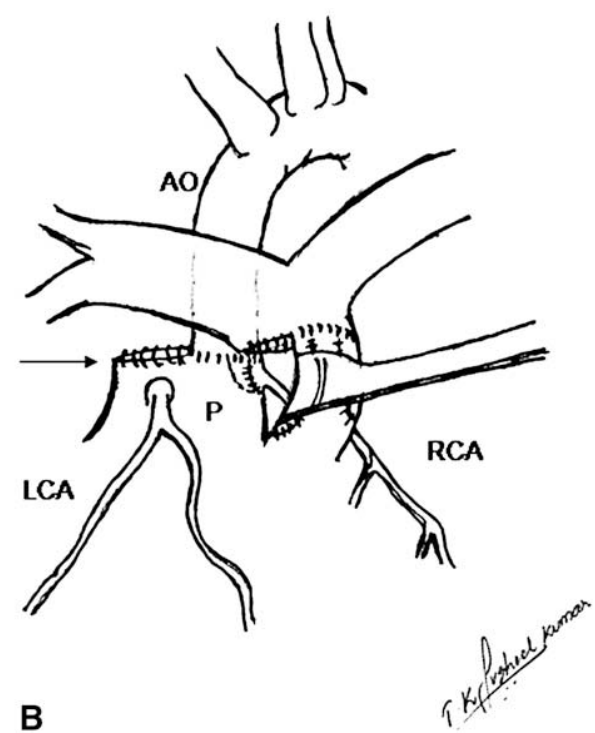

FIGURE E4. (A) Method of coronary transfer, construction of "keel" (arrow), and (B) final reconstruction after the ASO. Note the site of implantation of left and right coronary buttons to prevent kinking or stretching of coronary arteries and the shifting of the pulmonary artery anastomosis to the left to avoid coronary compression. For details see text. $A O$, Aorta; $L C A$, left coronary artery, $R C A$, right coronary artery; $P$, pulmonary artery. 